\title{
Rationales and Functions of Disliked Music: An In-Depth Interview Study
}

\author{
Taren-Ida Ackermann ${ }^{1} \&$ Julia Merrill ${ }^{1,2}$ \\ ${ }^{1}$ Max Planck Institute for Empirical Aesthetics, Frankfurt am Main, Germany \\ ${ }^{2}$ Institute of Music, University of Kassel, Kassel, Germany
}

\begin{abstract}
Author Note
Taren-Ida Ackermann https://orcid.org/0000-0003-0417-3067

Julia Merrill https:///orcid.org/0000-0001-9436-5219

We would like to thank Claudia Lehr and Freya Materne for help with recruitment of participants, and Melanie Wald-Fuhrmann and Lauren Fink for critical comments on the manuscript. T-IA conceptualized the research, did the investigation, and performed the formal analysis. JM and T-IA wrote the manuscript. Correspondence concerning this article should be addressed to Julia Merrill, Max Planck Institute for Empirical Aesthetics, Grüneburgweg 14, 60322 Frankfurt am Main, Germany. Email: julia.merrill@ae.mpg.de
\end{abstract}


2 Music serves to satisfy emotional and social needs. In its individual quality as liked or

3 disliked music, it can also be used to create and affirm one's own identity. While studies on

4 musical preferences are abundant, dislikes have rarely been considered in musical taste

5 research. The current study is centered on the rationales and functions of musical dislikes

6 using semi-structured interviews with participants from different age groups $(N=21)$. The

7 observed rationales for disliked music followed three main themes of (1) object-related

8 reasons such as the composition, the lyrics, and aesthetic dichotomies, (2) subject-related

9 reasons such as emotions evoked - or not evoked - in the listener, physical reactions, self-

10 related and normative reasons such as a mismatch with the self-image, and (3) social reasons

11 which reflect a rejection of the values presented by the music and its fans and therefore

12 underlining the importance of social distinction as a function of musical dislikes. Other

13 functions include identity expression, the avoidance of negative emotional and physical states,

14 and the implicitly expressed demonstration of musical competence. The explanations for

15 disliked music are based on both an excess or lack of certain qualities of the music or

16 emotional reaction to the music, pointing to the idea of a missing ideal mean of music.

17 Quantitatively, the rationales found relate to a combination of reference points which is

18 mainly the music, but often in combination with the lyrics, the performance, the artist, and the

19 fans. Further, the degree of dislike ranged from a slight dislike to strong hatred. To conclude,

20 musical dislikes are a complex, multidimensional component of musical taste. Taking musical

21 dislikes into account, the diversity and complexity of an everyday aesthetics of music can be

22 captured, extending our understanding of attitudes toward music and the functions of music.

23 Keywords: displeasure, social, rejection, attitudes, musical taste 


\section{Introduction}

With a few exceptions, musical taste has been researched via likes or preferences of certain types of music, painting an incomplete picture that cannot represent the evaluative diversity and complexity with which people approach, think and talk about their attitudes toward music. Understanding musical taste as an attitude, i.e., a general predisposition that is determined by a set of beliefs (opinions, positions, experiences) toward objects and leads to certain behavioral tendencies (Fishbein \& Ajzen, 1975), an in-depth approach with qualitative measures seems promising in order to survey the attitudes toward music that play a role in the everyday lives of listeners. The goal of the present study is to investigate how people explain their negative musical judgments and thereby, extend musical taste and preference research by including negative attitudes into the concept of musical taste.

Given that attitudes are formed by beliefs, knowledge, and earlier experiences, it seems plausible to conceptualize negative attitudes toward music as a result of prior negative experiences with certain music, of knowledge and beliefs about it, and as a mismatch with acquired general beliefs about what is good and desirable in music, i.e., the individual music aesthetics. That dislikes must be acknowledged as a relevant part of musical taste can be learned from Bourdieus's theory of social distinction (Bourdieu, 1984). Here, class-specific sets of liked and disliked music (and other cultural goods) are used as a resource for symbolic exclusion (Bryson, 1996; Lizardo \& Skiles, 2015, 2016). Further, the theory of omnivorousness today claims that higher social strata distinguish themselves from lower social strata by demonstrating broad cultural taste, i.e., by liking more (and disliking less) types of music (DiMaggio, 1987; Lizardo \& Skiles, 2012; Peterson, 1992; Peterson \& Kern, 1996).

While existing studies revealed which musical styles are often disliked and how they correlate with sociodemographic variables and, to a lesser degree, personality traits (Nave et al., 2018; Schäfer \& Mehlhorn, 2017), individual rationales for disliking a certain type of 
music have not yet been studied comprehensively - very much in contrast to musical likes.

Broadly, studies on music preference are based on two research approaches: On the one hand, researchers have been interested in which explanations are used by listeners to explain what they like, an approach that has been mainly pursued in qualitative studies (Berli, 2014; Greasley et al., 2013; Kunz, 1998; Parzer, 2011; von Appen, 2007). On the other hand, the focus has been on the study of the functions music serves for an individual, where (preferred) music is evaluated by its suitability to certain purposes and on the use of music in everyday life (Boer et al., 2012; Greb et al., 2017; Hargreaves \& North, 1999; North et al., 2004; Schäfer \& Sedlmeier, 2009; Sloboda et al., 2001). While the first approach helps with answering the question of why participants like a particular music, a focus on functions and uses sheds light on the question of why participants generally like and listen to music.

Hence, the question arises as to which explanations are used for disliked music and whether functions other than social distinction exist. In some studies, the topic of dislikes came up with some of the participants (and were often reported parenthetically), pointing to certain similarities in explanations for musical likes as reported above. First, as a reason for disliked music (often either entire styles or specific songs), participants reported on musicrelated and performance-related aspects such as missing variation (Anttonen, 2016; Cunningham et al., 2005; Greasley et al., 2013), repetitiveness, lack of complexity, incongruous or unexpected elements, missing (harmonic, melodic) resolution (Cunningham et al., 2005), and specific sound qualities (too loud, distorted, sound of instruments) (Peltola \& Vuoskoski, 2021). Missing variation in the lyrics was also mentioned, i.e., meaningless or aggressive (Greasley et al., 2013), overly simple (inane, stupid) and repetitive lyrics, overly sentimental or clichéd, misogynous sentiments and other biases, and contradictory or intelligible messages (Cunningham et al., 2005). The voice of the singer was also subject to critique, mainly the singing characterization (annoying, yowling, monotonous, whiny), overdramatic vocal effects (Cunningham et al., 2005), high-pitched voices, a nasal sound, or a 
death-growl (Merrill \& Ackermann, 2020; Peltola \& Vuoskoski, 2021). The inability to sing along and missing variety between artists were also criticized (Greasley et al., 2013). Other reasons for dislikes pertained to perceived effects of the music on the listener and included unpleasant bodily feelings of disgust, nausea and pain, the perceived risk of physical harm, muscle tension, aggression, and the urge to escape (Parzer, 2011; Peltola \& Vuoskoski, 2021). “Inauthenticity” was also a reason for disliking music, as participants report on missing originality and honesty in the emotions and topics expressed in the music as well as copying other styles and artists in order to misuse this for their own success (Anttonen, 2016; Frith, 2004; Grazian, 2010; Kunz, 1998; Moore, 2002; Parzer, 2011;

Peterson, 2005). A supposedly strong focus on commercial success was also mentioned to foster a dislike (Frith, 2004; Greasley et al., 2013), and a pretentious behavior by the artists ("wannabes and posers"; [Cunningham et al., 2005]). Aspects of production and certain forms of behavior and content ("sex and violence") and supposedly negative effects of music on people/the youth and incompetence were criticized and disliked (Frith, 2004; Greasley et al., 2013). Further, painful and negative memories or experiences can lead to avoidance of certain music, and finally, the situation and context have an influence on the participants' ability to bear their disliked music and determine how to react to it (Cunningham et al., 2005; DeNora, 2000; Peltola \& Vuoskoski, 2021).

Based on these various and often single findings, a large range of reasons can be expected to account for the dislike of all sorts of music, such as peoples' music aesthetics, earlier experiences with certain types of music, and general attitudes, views and beliefs. As the reported findings were rather a parenthetical product of studying musical preference, the current research took a qualitative approach with in-depth interviews to cover this expected variety. 


\section{Degree and Types of Disliked Music}

Further findings suggest that there exist differences in the intensity of dislikes.

Comments in online forums presented a range of judgments from mild rejections to vehement hatred and disgust of certain music (Parzer, 2011, p. 179), and people were reported strongly reacting to their musical dislikes and not simply giving neutral or ambivalent responses (Savage, 2006). Another study found two "listener types," one with a strong negative attitude and one with a rather neutral attitude toward the "aversive" music, showing that the first group experienced much stronger physically unpleasant feelings, a threat to their own musical identity and a violation of social and moral rules in response to aversive music than the other group (Peltola \& Vuoskoski, 2021).

Likewise musical likes can range from a mere "like it" to absolute love, one can expect that musical dislikes range from a mere "don't like it" to hate. Therefore, the current study will investigate the reasons behind different degrees of disliked music.

Typically, studies on musical taste refer to music genres that are commonly used categories in everyday parlance and are thought to distinguish between types of music based on stylistic components, origins, aesthetics, meanings and represented social groups (Fabbri, 2012; Samson, 2001). From a musicological point of view, one would rather call such types styles, whereas genre is typically defined as a type of composition that is characterized by its form, instrumentation, and function (e.g., Opera is a genre within the style of Classical music, whereas song is a genre that exists in almost any style). In the current study, the terms style and genre are used in their musicological sense, where participants reported a variety of musical dislikes, from general musical styles and genres to specific artists, albums, and individual songs.

\section{Functions of (Disliked) Music}

The most common and clearly described function of positively valued music is its use in influencing one's emotional state and mood (Lonsdale \& North, 2011; Tarrant et al., 2000). 
126 Self or identity-related functions are also very important. In addition to identity construction,

127 especially in adolescence (Ackermann, 2014, p. 113; Hines \& McFerran, 2014; Laiho, 2004),

128 other functions include identity management, expression and reinforcement of individual

129 values and attitudes, self-reflection and exploration, and trying out and expressing different

130 aspects of personality (Dolfsma, 1999; Rentfrow, 2012; Schäfer \& Sedlmeier, 2010) as well

131 as finding meaning in life, or absorption and distraction from reality (Schäfer et al., 2013).

132 Functions of musical dislikes seem to be less straightforward identifiable, because

133 typically, people do not listen to music they disapprove of. In communicating one's attitudes

134 toward music, however, such functions can be found in adolescents, where music is used to

135 differentiate from other groups in order to discriminate the 'out-group' and at the same time to

136 enhance the status of the 'in-group' and to increase their self-confidence (Tarrant et al., 2000).

137 Not only are the listeners of the other music discriminated against, also, the fans of the same

138 (liked) music are valued higher than the fans of the disliked music (Bakagiannis \& Tarrant,

139 2006; Lonsdale \& North, 2009). Interestingly, within the in-group, it was still accepted if

140 single members showed deviating attitudes and preferences, because the highest possible

141 individuality and inadequateness within the group was valued (Becker, 2014).

142 One study explained the avoidance of aversive music with the process of emotional

143 contagion (Peltola \& Vuoskoski, 2021): The negative emotional and physical experience

144 (through a mimicry of the music) might be interpreted as the function of disengaging with the

145 music - which is then found aversive and disliked (note that cause and effect are hard to

146 disentangle). These and other possible functions of musical dislikes need evaluation.

\section{Musical Value Judgments}

148 It could be seen that sociological musical taste research included both liking and

149 disliking of musical styles, since both are essential for social distinction and cohesion.

150 However, there is also an individual, differentiated aesthetic judgment, which goes beyond a

151 flat rejection of musical styles and the link with socioeconomic factors. Psychological studies 
152 of musical taste have investigated the functions and use of music and therefore, have been

153 dominated by the study of musical preferences. This is where the current study comes in and

154 explores the rationales for disliked music, which are the verbalized, individual reasons for

155 disliking music. These rationales are based on an individual aesthetics, which can refer to

156 different types of music and can include various reasons for disliking music.

157 Particularly relevant for the current study in this regard is a model on musical value

158 judgements (Behne, 1986, 1987; further defined by Kunz, 1998), which relates to the

159 aforementioned attitudes toward music. Value judgments take place between three

160 dimensions: The ME (germ. ICH) judgment, i.e., the subjective level of judgment that

161 includes personal liking, often based on prior experiences, and emotional and psychological

162 functions, the IT (germ. SACH) judgment, that is judgments based on musical properties such

163 as melody and rhythm, and the individually acquired idea of 'good' music, and YOU (germ.

164 MAN) judgments, that is judgments in terms of social validity, which refers to the society as a

165 whole but also to specific groups.

166 This model is of particular interest as it focuses on value judgements in which positive

167 and negative judgements find their place, and as it does not already integrate the different

168 reference points of rationales into the category system itself (such as particular musical styles

169 or pieces). Therefore, it provides a frame for the present study on the psychological

170 mechanisms of disliked music in which the participants' explanations of their judgements

171 were the focus.

172 The Present Study

173 The present study focuses on disliked music and takes a broad approach to cover

174 explanatory strategies related to personal dislikes. The study used in-depth interviews and

175 followed research questions on (a) Which types of music are disliked?, (b) the explanatory

176 strategies, i.e., how do the participants explain their musical dislikes?, (c) the impact of the

177 participants' musical dislikes, i.e. how do they react when confronted with this music or when 
178 they meet someone who likes this music?, (d) the extent to which the participants see a

179 relationship between their musical dislikes and their self-image, (e) the strength of dislike,

180 i.e., are there differences between the individual dislikes? Are some dislikes stronger than

181 others?, (f) What functions do musical dislikes fulfill?

182

183

184

185

186

187

188

189

190

191

192

193

194

195

196

197

198

199

200

\section{Methods}

\section{Ethics Statement}

All experimental procedures were approved by the Ethics Council of the Max Planck Society, and were undertaken with written informed consent of each participant.

\section{Choice of Research Method}

The basic principle of interviewing is a mindset of understanding participants as experts on their own experience and knowledge of the topic (Holstein \& Gubrium, 1995).

Therefore, in a semi-structured approach (Banister et al., 1994; Leech, 2002), the questions in the interview guide were used mostly as structuring elements in a flexible, advisory way rather than as binding wordings in order to react and communicate openly and flexibly with the interviewees (Misoch, 2015). Questions were constructed in a non-suggestive and neutral way that encouraged the participant to answer in full sentences.

Musical preferences change throughout one's life and music, in general, does not always retain the same value in different phases of one's life (Bonneville-Roussy \& Rust, 2017; Chamorro-Premuzic et al., 2012; Lonsdale \& North, 2011; Schramm \& Vorderer, 2002). Therefore, care was taken to ensure that not only young adults and students were interviewed, but that a broad age spectrum was covered, using a stratified sampling approach with five different age groups. It is of note that no longitudinal effects can be covered with this cross-sectional approach. 


\section{Participants}

Participants were recruited via a pool of previous participants at the research institute, through the webpage of the institute, social networks (Facebook, Twitter), and flyers and posters in the city of Frankfurt am Main, Germany (libraries, community college).

Age groups consisted of four participants each with equal gender distribution and were grouped in blocks of ten years of age, starting at 18. The last group consisted of interviewees aged 58 and older. One pretest was conducted, and because no changes had to be applied to the interview process, it was included in the main sample, adding to the number of participants (total $N=21$, eleven female, mean age $=41.42, S D=14.26$, range 18-64 years). Therefore, the second age group consisted of five participants. Among the participants were eight students, five self-employed, five employees, a housewife, a doctoral student, and a pensioner. Nine of the participants had as highest educational attainment a High School diploma, twelve a university degree. Seven participants were professionally involved in music, 13 played an instrument.

\section{Procedure}

After filling out the forms for data protection and giving consent about the recording of the interview, demographic data were collected (gender, age, education, profession, and musical activities) and participants were informed about the aim of the study and the procedure of the interview. The interviews took place in a room with a living room atmosphere. All interviews were conducted in German by the first author and all interviewees were native speakers.

Interviewees were asked beforehand to prepare a list of their disliked music. No instructions were given about how many items and what kind of music were to be prepared. For each item on the list, systematic questions were asked about the reasons for disliking this music, what the participant associates with this music, how they react when they come into contact with it, and what they think about the people who like it (see interview guideline in 
supplement). After all items had been reviewed, participants were asked to rate the strength of dislike of all their disliked music on an 11-point scale from neutral to most severe dislike. Afterwards, on a more general level, it was asked how the dislikes had developed and whether any changes had occurred, whether friends and social contacts shared the dislikes and to what extent the judgments of others influenced one's judgment of music.

In a final phase, the interviewees were given the opportunity, still with ongoing audio recording, to make concluding comments and further remarks on the questions asked and topics discussed (Legard et al., 2003; Misoch, 2015). Interviews took about 50 to 100 minutes and monetary compensation was $15 €$.

\section{Qualitative Content Analysis}

Qualitative content analysis is a method for analyzing qualitative data, mainly texts, in order to enable a structured description of the data. This is done by creating categories in a differentiated system and connecting them with passages in the text via codes. In doing so, the categories are firmly grounded in the data and therefore embedded in their context of communication (Kaufmann, 2015; Mayring, 2014; Schreier, 2014; Steigleder, 2008). To ensure that the complexity and range of participant's dislikes and rationales were captured in the analysis, two sub-methods of qualitative content analysis were combined: In essence, a structuring content analysis was used as a mostly theory-driven approach for the main categories and combined with inductive category creation out of the interview data.

\section{Transcription and Coding}

Transcription of the interviews was done manually and the coding was done with the software Atlas.ti, version 4.5. Transcription guidelines included accurate coding without any dialect, punctuation adjustment to written German, anonymization of all personal data, notation of breaks with duration, and notation of sounds like laughing or shouting in parentheses. 
Before coding, all transcripts of the interviews were read through at least twice to make sure the content was well known to the coder. Based on the theory driven research questions and the resulting level of abstraction, categories were gradually developed inductively from the material. These categories were described using anchor examples and definitions and subsumed either under existing categories or included in the code system as a new category. The categories were revised at fixed intervals and summarized as needed. All decisions regarding the merging of categories, but also all considerations, questions, difficulties, and ambiguities regarding specific codes, were documented in the form of memos.

Data is provided as supporting information. It includes the codes and their translations from the interview study per participant and per category, Full quotes are published in the German dissertation by the first author (2019).

\section{Results}

\section{Descriptive Analysis}

The first analysis step is descriptive in nature and uses a) the lists the participants prepared for the interview sessions, and b) the dislike ratings they provided per item on the lists on an 11-point scale. Conclusions were drawn based on these observations, that is on the types of disliked music, degree of dislike, and the reference points of musical dislikes.

\section{Types of Disliked Music}

Using the prepared lists and verbal additions by the participants, a total number of 277 musical dislikes was counted, which ranged from 8 to 36 per participant with an average of 13 dislikes (see Fig. S1, supporting information). In order to account for this skewed distribution, the data was first averaged within participant and then across participants (see Fig. S2, Table S1, supporting information). On average, the most often mentioned type of dislike was musical style (44.4\%), followed by artist (29.1\%), genre (13.1\%), specific pieces $(6.1 \%)$, 
277 individual instruments (3.9\%), musical characteristics (2.8\%), and musical formats such as 278 music-based TV shows $(0.7 \%)$.

279 Schlager was the most frequently mentioned disliked style, while several substyles 280 from Electronic Dance Music (EDM) were disliked such as Techno and House. The most 281 disliked artists were from Rock music, and the most disliked genres belonged to Classical 282 music (e.g., Opera). The majority of the single pieces listed belonged to Classical and Pop 283 music (see Table S2, supporting information).

\section{Degree of Dislike}

The dislikes on the lists were rated on an 11-point scale on the degree of dislike $(N=$ 241), when applicable. Most frequently, the interviewees gave the most substantial dislike ratings (modal at 10 and 9 with 38 nominations each; see Fig. S3). The high degree of dislike (ratings $\geq 6$ ) accounted for $63.1 \%$ of all dislikes evaluated. Even though the frequency distribution of the dislikes was thus clearly skewed, the participants used the range of the rating scale (see Fig. S4 and Table S3).

\section{Reference Points of Dislikes}

Before going into the rationales of disliked music itself, the actual reference points of the rationales had to be clarified, following the questions, a) to which aspects of the respective music does the dislike refer to?, and b) do the participants dislike the music as a whole, or can they name individual aspects on which their dislike is based?

Five main reference points were identified for describing musical dislikes during the interviews: the music itself, lyrics, performance, artist, and the people who listen to it. The majority $(84.8 \%)$ of the rationales for disliked music were related to the music in combination with one or more of the other categories, and $40.4 \%$ of all dislikes were only justified because

300 of the music and not because of other references to the lyrics or extra-musical categories. $32.9 \%$ of the rationales were related to the lyrics in combination with other categories, but only $2.2 \%$ solely to the lyrics. In the case of vocal music, music and lyrics cannot be 
303

304

305

306

307

separated, also because the voice of the artist does not only transfer content, but also sound qualities and emotions, and is therefore part of the musical expression (Frith, 1987; Peltola \& Vuoskoski, 2021; von Appen, 2007, p. 92). The artist is another reason for disliking music, which was the case in $31.4 \%$ in combination with other categories; in only one case the artist itself (the person) was the reason for the dislike. The participants referred to the listeners or fans of the disliked music in $20.2 \%$ of the rationales in combination with other reasons (in only $1.1 \%$ solely to the fans). The performance as a reason for a dislike (e.g., clothes, dance styles, TV formats, location, and setting) was used in $15.9 \%$ of the cases in combination and in only one case solely (see Table S4 and S5).

It is of note that these categories overlap and a clear separation is often impossible. Adding up the combinations of reference points without the music, the combinations amount to $12.3 \%$ (34 of 277), and adding up the combinations without the music and the lyrics, they amount to $5.8 \%$ (16 of 277). Hence, only a small percentage accounts for combinations between the artist, the listener/fan, and the performance. While $58.5 \%$ of the combinations include the music without the lyrics, only $6.5 \%$ include the lyrics without the music, and $26.4 \%$ include both. This shows that, typically, rationales for disliked music relate to a combination of reference points and only a few dislikes relate to only one particular point of reference.

Note that this was a purely descriptive analysis of the prevalence of reference points of rationales for disliked music. The reasons revealed in the following qualitative analysis relate to or coincide with these reference points, for example, the lyrics can be a reference point as well as a reason for the dislike itself. A person can dislike the lyrics because of the content or because of negative feelings evoked by it. It is also of note that this analysis does not show which reasons are more or less important or used more or less often. 


\section{Qualitative Analysis: Rationales for Disliked Music}

The qualitative analysis revealed the following categories of rationales for disliked music: (a) music-compositional aspects, (b) performance, (c) aesthetics, (d) the lyrics (theme: object-related reasons), (e) emotional, (f) bodily or (g) normative/self-related reasons (theme: subject-related reasons) or (h) social reasons focusing on social cohesion and distinction (theme: social reasons). While the categories were inductively created out of the material, the themes mentioned here were applied post hoc and are based on (Behne, 1986) (also found in a similar way in [Kunz, 1998]); these fit the current data and were found helpful to show the dimensions of value judgments in music.

\section{Object-Related Reasons for Disliked Music}

Music-Compositional Aspects. The participants referred to the melody, harmony, rhythm, structure/form, and loudness of the music. The disliked music was perceived as tuneless ("non-melodic"), "too melodic" and evaluated as "kitsch" (hokeyness) along with melodies being "not beautiful," "too soft," or "too smooth." As melodic and harmonic features were often criticized together, music was likewise disliked if it was perceived as too “inharmonic," "dissonant," or "harmonically unfamiliar." Concerning tempo and rhythm, participants criticized a too fast or slow tempo as well as too dominant, or not sufficiently pronounced, or monotonous rhythm. A varying rhythm as well as rhythm with a stimulating, thrilling effect, was described as something positive and desirable and if this was not given, the music was evaluated negatively.

Similarly, participants disliked music that did not have a clear or comprehensible structure, which was described as "abstract," "drifting apart," or as "noise." In addition to a lack of structure, music was criticized when its form was perceived as "too simple," "cheap," or "predictable." Some participants described a perceived loudness (not the actual adjustable volume) leading to unpleasant physical reactions. 
Note, while in this analytical presentation following the content analysis these different ways of reasoning were presented separately, the participants mostly mixed and combined them to describe their dislikes. For example, a melody that is perceived as too simple usually goes hand in hand with a too simple and uniform rhythmic structure.

Performance. Other reasons for dislikes focused on performance aspects, such as the sound of specific instruments, which usually referred (rather broad and unspecific) to the overall sound of an instrument or piece as a whole, but also the singer's voice, where the sound, the expression, and technique of the singer played a role (ranging from a "broken sound" to "shouting" or "shrieking").

Aesthetic Dichotomies. The explanations entailed general aesthetic categories, which can be applied to several aspects of the music and the lyrics. It needs to be considered that aesthetic criteria always depend on the discourse and are time-bound: While stylistic consistency is specifically valued in certain epochs (such as in the baroque) and within individual styles and associated subcultures (e.g., Country or Traditional German music (typically from the Alps region) and substyles of EDM), individuality and innovation are an essential part of the aesthetics and standards of other styles. Therefore, the aesthetic dichotomies now presented are used as an expression of the individual aesthetics of the participants and not as music-inherent qualities.

In the dichotomy variety and uniformity, the participants rated uniformity much more negatively than variety. Lack of variety or diversity was criticized in whole styles or genres as well as in individual musical elements such as rhythm or bass lines. Music was also disliked if the participants could not perceive significant differences between the different pieces of a style or an artist, of which "everything sounds the same." This means that both uniformity within a piece as well as uniformity between pieces were disliked.

In the dichotomy of complexity and simplicity, the participants criticized when music or individual aspects of the music were too simple (with clearly derogatory terms such as 
378 "cheap," "flat," "primitive"). The level of differentiation of the statements was very different:

379 While some respondents criticized the music of the disliked artist or composers as too simple,

380 others referred to particular harmonic sequences ("tonic, dominant, subdominant") or to a

381 specific aspect such as the lyrics. Complexity in itself was not necessarily a positive

382 characteristic of music for the participants. If the music becomes too sophisticated in its

383 structure or sound, the listener may feel overwhelmed. It also seems to be essential to be able

384 to "understand" the music. Behind this is the desire to be offered formal structures that are

385 simple enough to remain catchy and understandable, and at the same time, sufficiently

386 complex to provide inspiration and not become boring.

Related to innovation and reproduction, in most cases, experiments and new ideas

were evaluated positively by the participants, and their absence was criticized. The

389 participants argued for the most part with a mixture of musical similarity ("this is all the same") and description of effect ("boring"). In some cases, however, they also criticized music covers and the use of existing melodic lines in other pieces in order to appeal to larger

392 groups of listeners. Occasionally, participants also complained about the excessively

393 experimental character of pieces.

394 The strongest form of musical dislike is possibly the denial of certain music actually

395 being music ("this is not music"). By denying certain forms of music the status of music,

396 participants deny not only its musical character but also any value that separates music as an

397 art form and created work from mere noise ("for me, that is noise and not music"). This

398 judgment was mentioned in the context of several other categories and is therefore

399 categorized as cross-theme.

Lyrics. Both the content of the lyrics as well as linguistic features were an issue to the

401 participants. Disliked lyrics were perceived as too simple, too superficial, or unrealistic. In

402 this kind of criticism, lyrics (particularly in Schlager and Traditional German music) were

403 accused of taking up specific topics such as love, home, closeness to nature, or friendship, 
which were perceived as "clichéd" or "simple-minded," as a representation of a "perfect world," "ideal image" or "as in a fairy tale," but not as a realistic representation of real relationships or honest feelings. Further aspects of the lyrics are discussed under "normative and self-related reasons."

\section{Subject-Related Reasons for Disliked Music}

Emotional Effects. A difference in explanations could be seen between the emotions perceived in the music and evoked by the music (Schubert, 2013). The more different these two loci of emotions were, the more the participants themselves differentiated between the emotional expression of the music and their feelings. The most frequently mentioned perceived emotions in the disliked music were aggressiveness or anger, which were criticized mainly in the styles of Metal or Hip Hop, but also cheerfulness or good mood, which were most often mentioned in Schlager (in addition to not being honest or authentic).

In contrast to perceived emotions, the emotion felt was clearly in the negative valence range. Some participants reported that music can make them aggressive both by a match and a mismatch of both loci (e.g., the happy expression of Schlager making them angry). Others said that individual dislikes were caused by the music making them "sad," "dragged down," or "depressed." These feelings shared a representation of emotional states that the interviewees perceive as negative and inescapable, and accordingly, dislike music that makes them feel this way. In addition to specific negative feelings, some participants also described a general decrease in their mood as an effect of their disliked music, which they said can sometimes last for some time.

Another often mentioned emotional reason for a dislike, however, was if the music “does not address" or "does not touch" them. In this case, respondents described disinterest or boredom as a reaction. Even if this lack of emotional effect did not induce a negative effect in the listener, it was evaluated negatively and led to a dislike of the respective music. 
Bodily/Physical Effects. In addition to emotional effects, participants reported unpleasant physical reactions to music. These descriptions remained rather general and 431 imprecise: the music was "unpleasant," "exhausting," or "does not do one well." In most

432 cases, the participants used it to describe a state of general tension or exertion that they find 433 genuinely unpleasant. In a sense, music acts against their will on them and their bodies 434 ("harassment") without them being able to escape it. For some participants, this feeling of 435 physical discomfort is related to the volume of the music, for others the overall sound. In addition to general discomfort, however, individual participants also report specific physical symptoms in response to the disliked music such as headaches or pain in the ears, but also nausea, a racing heart, uneasiness, and intense tension.

In addition to the negative effects of music described above, participants criticized a discrepancy between desired and actual effects. This is primarily about a lack of physical activation such as lack of "danceability" or other physical stimulation.

Self-Related and Normative Reasons. The reasons in this category can be roughly divided into two subcategories: First, participants referred to certain, mostly negative, experiences in their past, and an excessive exposure of previously positively or neutrally assessed music (which was "heard too often") that led to the dislike (self-related reasons). Second, they justified their judgments based on their self-image and related attitudes, which conflicted with attitudes associated with the disliked music (political, religious, or moral attitudes; normative reasons). Some participants described a rather broad discrepancy between their self-image and the qualities attributed to music, without going into the details of which qualities of music do not "fit." Others, however, stated in more detail which aspects of the music were incongruent with their own opinions or values (based on song lyrics or other signs), mainly referring to artists who are clearly politically classifiable. 
categorized as cross-theme. Music is "good" if it is "an expression of personal things" and transports "honest" feelings and does not serve the "interests of the music industry." Hence, a lack of authenticity was closely linked to the aspects of mainstream and commerce. Behind the criticism of certain music taken as "inauthentic" was, in most cases, the claim that music as an art form should be independent of economic success and trends. Compromises by artists who are guided by market interests were therefore disliked, as are deals with overpriced concert tickets and merchandise. At the same time, the artists' attitude towards their music and the market itself was also evaluated, as they are required to perform out of belief and identify with their music instead of routinely "doing their job."

The attribution "not authentic" was also used in an emotional context. Participants expected that the emotions presented in the music either describe the emotional life of the artists themselves or are a realistic reflection of emotional states that they know and can comprehend. If neither one nor the other is given, the interviewees perceived the emotional content of the music as "wrong" and "exaggerated." Some participants emphasized the subjective character of this criticism: they individually do not feel addressed by the music, or rate the music as not honest or exaggerated. This means that the focus is less on distancing oneself from other listeners than on the need to identify with the content and emotional expression of the music or the artists and their environment, or at least to agree with them in their requirements of art and music. Accordingly, music that does not meet these requirements or does not offer sufficient potential for identification and agreement is regarded as inauthentic.

\section{Social Reasons for Disliked Music}

The social reasons could be divided into arguments that refer either to one's social environment and the taste judgments common to it (in-group) or to other groups of which the participants do not feel part of (out-group). These justifications were often connected with 
480

481

483

484

485

486

487

488

489

490

491

492

493

494

495

496

497

498

499

500

501

502

503

504

prejudices and stereotypes about the corresponding group. In-group and out-group reasons were also not mutually exclusive and were sometimes used to complement one another. Membership of a particular social group, be it family, friends, or the general social environment, determined only a relatively small part of the reasons for dislike. Defying a code of attitude and judgement about the common dislikes in the group would potentially lead to consequences for the individual in that their reputation and standing would suffer ("one is not allowed to find it good," "that is simply uncool, so to speak"). The disliked music can also refer to a certain level of education within the in-group ("no one who has any sense or taste at all listens to such things").

Stereotypical attributions played an essential role in the distinction between the listeners, fan groups, or artists of the disliked music and the outside world. Of great importance here again was the political attitude of the musicians and fans, in addition to the associated educational level and the attributed character traits, which were, in most cases, more or less explicitly formulated stereotypes. Participants also evaluated the bands and singers in terms of how likable they appear and how they present themselves in interviews or at concerts. Disliked styles that were closer to certain subcultures than others offered additional starting points for stereotyping. A good example is Heavy Metal, whose fans express their musical preference in the form of clothing ("band T-shirts and dark colors") and appearance ("long hair, beards"). In the interviews, several participants expressed prejudices against the Heavy Metal listeners and musicians and often had negative associations. In addition to certain, mostly negative, character traits, the interviewees also attributed psychological abnormalities or disorders to the fans or associated them with substance and alcohol abuse or criminal behavior. However, in most cases, it was more about sympathy and the general impression that the artists made on the interviewees. These impressions were generated by the pseudo-knowledge the participants had mostly gained through social media. 


\section{Reactions to Disliked Music and its Fans}

The reactions described by the participants could be divided into four categories. On the one hand, they reported (1) emotional and (2) physical reactions to the confrontation with the disliked music, which were already presented as an unpleasant effect of the music. On the other hand, they reported (3) action implications and (4) social reactions in the case that they met someone who appreciated the disliked music.

While some dislikes could be tolerated by the participants for a certain time, others led to clearly described avoidance behavior. If certain disliked music was played, participants either changed the music or switched it off or even left the room. With stronger dislikes, they also avoided places where they would be confronted with the music such as certain clubs, discos, and parties. It was unanimously described that the social environment can influence one's behavior toward disliked music: Accompanied by friends, several participants reported that disliked music was more tolerable. In most cases, participants said that someone else's preference of their disliked music would have no effect on them, or that they would even respond positively. Only in the case of differences in (political or religious) attitudes they would also avoid the supporters of their disliked music and, if necessary, break off a conversation if their counterpart was to identify themselves as a fan.

\section{Discussion}

The results show a wide variety of rationales for disliked music and extend previous findings from musical taste research. Participants report on various musical dislikes to different degrees using explanations that represent three major themes of musical value judgments, i.e., the subject, the object, and the social. Broadly, music is disliked if it does not comply to ones beliefs, the self-image, or the individual aesthetics, i.e., what one expects from the music. Thus, this study succeeded in showing that musical dislikes are a complex, multidimensional component of musical taste and not just the negative antithesis of musical preferences. The current findings provide further confirmation that surveys of musical taste 
531 working exclusively with musical style categories omit some of the types of music used by

532 listeners and thus a substantial part of the participants' musical tastes.

\section{Rationales for Disliked Music}

Although disliked styles form the largest share among the listed "musical dislikes,"

535 the participants also report on artists, pieces, existing as well as made-up genres, certain

536 instruments and musical characteristics. Further, the analysis of the reference points of the

537 rationales (i.e., what a specific reason is actually referring to), showed that a large part of the

538 reasons for disliked music relate to the music itself (in about $40 \%$ of the cases) and to the

539 music in combination with other reference points such as the lyrics, the artist, and the

540 fans/listeners of the music (about 85\%).

541 The rationales comprise reasons that describe the object (e.g., musical features or

542 aesthetic dichotomies), the subject, and/or the social environment. With regard to subject-

543 related or self-related reasons, dislikes are used to keep music away from oneself and one's

544 identity, which associated content, characteristics, or behaviors do not match those of the

545 listener. This interpretation is confirmed by the participants, who see correspondences

546 between their self-image and their negative attitudes toward certain music.

547 Social reasons in the present study focus on the participants' reasons specifically

548 related to other people and the social environment. Reasons related to the out-group, fed by

549 stereotypes and prejudices about the fans and listeners of the disliked music, were more

550 frequent than reasons related to the in-group. The dislike of certain types of music served in

551 this context to strengthen the inner cohesion of the group by confirming the existence of

552 clearly defined antagonists and associated values which one shares and may defend

553 externally. The categories derived from the interviews are summarized in Table 1. It is of note

554 that the categories presented show overlap, and the participants combine different categories

555 for the dislikes. In some cases, it is also difficult to distinguish purely negative descriptions of

556 the music from reasons for the dislikes. In addition to the three major themes presented, three 
557 cross-theme categories can be found in the explanations of the participants, which contain

558 aspects of all themes, that is authenticity in combination with marketing strategies, and the

559 reference to certain music as kitsch and as noise or "non-music".

$560 \quad$ Table 1

561 Rationales for Disliked Music

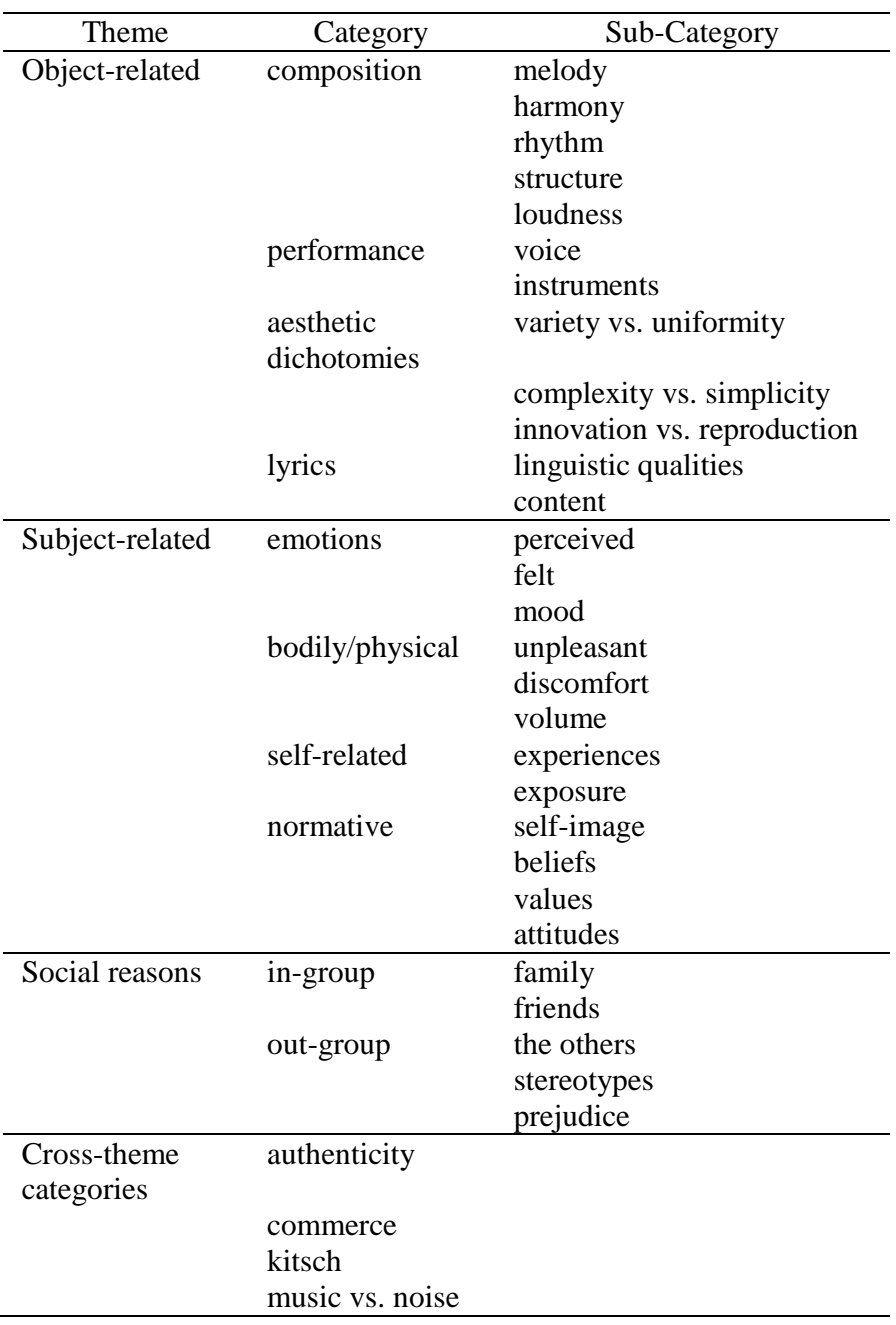

\section{Missing an Ideal Mean of Music: Too Much or Too Little}

In many cases, the respondents justified their dislikes by using deviations from an

565 ideal expression of certain characteristics, that is "too much" or "too little." A similar

566 observation was made in another study, which found judgments of various likes and dislikes

567 referring positively to the "correct" extent of a characteristic (Woodward \& Emmison, 2001).

568 This insight is used in consumer research in the form of the "just-about-right scale" (JAR- 
scale; [Popper \& Kroll, 2005]), which evaluates the properties of an object with an ideal center ("just about right") between the endpoints "too much / too strong" and "too little / too weak," which has been used in music-related studies evaluating piano (Kroger \& Margulis, 2017) or vocal performances (Merrill \& Larrouy-Maestri, 2017). However, it does not seem that both deviations are equally relevant for all characteristics of disliked music. Participants also reported that certain negative deviations can, to a certain extent, be compensated for by other positive characteristics.

This interrelation of a "too much" and "too little" is reminiscent of Berlyne's idea of the inverted U-shape to explain preference occurring with arousal potential. Here, collative variables such as familiarity and complexity are usually taken into account (Chmiel \& Schubert, 2017), but the current results point to the idea that listeners expect an optimal experience which equates to being optimally aroused and engaged by many different variables (Berlyne, 1960; Csíkszentmihályi, 2008). This is at least the ideal they seem to be striving for in order to like the music. One variable directly points to the findings around the inverted Ushape, that is, participants report a dislike because they "have heard it too often", which leads to displeasure due to over-exposure.

\section{Functions of Disliked Music}

For the musical preferences of Western listeners, several studies have shown that positive judgments of certain music are closely linked to its fulfillment of certain functions (Boer, 2009; Getz et al., 2011; Schäfer et al., 2012). Especially the possibility to express one's own identity by means of music, but also the use of music to establish contact with others, its ability to trigger strong positive emotions, or to express one's own values in it, determine the strength of the preferences (Schäfer \& Sedlmeier, 2009).

These functions (partly in a reversed manner) can also be found for disliked music even though the current participants hardly ever directly use functions to describe their 
594 dislikes. Hence, the functions of disliked music have to be inferred from the participants' 595 explanations. First, as with liked music, identity expression plays a major role. Many participants

597 drew direct parallels between their self-image and the characteristics and attitudes in the 598 music, which they describe as not fitting or belonging to them. Hence, the disliked music 599 serves the self-presentation in social contexts, but is equally relevant as a psychological 600 process for strengthening one's own self-image and self-esteem by distancing oneself from 601 the negative self (Ogilvie, 1987).

Two related functions of musical dislikes represent the avoidance of negative

603 emotional and physical states as well as negative or painful memories triggered by the music.

604 This can be interpreted as the opposite of the function of mood management (Schäfer et al., 605 2013), and mind wandering and reminiscence in preferred music (Greb et al., 2017).

606 The most indirect function of musical dislikes might be the demonstration of musical 607 competence: Calling music "bad" or denying it the status of actually being music or by calling 608 it noise as well as criticizing certain musical aspects, serves emphasizing one's own 609 knowledge and "good taste.” By communicating one's own musical standard and 610 requirements of "good music," the participants communicate their musical education, and the 611 extent of their musical taste and by this, inform about the cultural capital they possess (Berli, 612 2014; Bourdieu, 1984; Parzer, 2011). The expression of one's own musical competence is 613 thus closely linked to the function of creating and strengthening social cohesion and 614 distinction.

615 Criticism related to authenticity and commerciality is also related to social distinction. 616 If the liked music becomes too successful, it loses its function as a distinguishing feature that 617 creates (group) identity and is rejected. In addition, the dislike of music with contradicting 618 political, moral, or religious stands also serves to position oneself in society (e.g., as anti619 fascist or left-wing). Rejecting certain music for these reasons means likewise avoiding places 
620 and events with this music, and therefore the risk of socially engaging with people who

621 identify with these opinions.

622

\section{Types and Degree of Disliked Music}

Foremost, participants reported on the dislikes referring to musical styles (44\%) and artists (30\%). While on the level of styles, primarily Schlager, Traditional German music and Metal were disliked, the substyles were mainly from EDM, non-European music, Metal and Rock. The disliked artists were predominantly from Rock, Pop, Schlager and Classical music. Three observations can be made from this: First, Schlager, Traditional German music and Metal were also among the most disliked styles in other studies (e.g., Schlager and Traditional German music in Germany; [Lehmann, 2018], and Metal in the US; [Bryson, 1996]; for more recent dynamics of dislikes among different age groups, see Lizardo \& Skiles, 2015). Second, naming certain artists needs a certain level of familiarity with the style, which is the case for Pop, Schlager and Classical music to an extent, which make use of the celebrity focus in the media. Notably, people can dislike an artist or a genre within a generally liked musical style, which has consequences for future musical taste studies. Third, the findings show how important it is to not only focus on style evaluations but also on genre evaluations within a style. In Classical music, for example, dislikes of the overall style seem to be rare (Bennett et al., 2010; Bryson, 1996; Savage, 2006), but disliking individual artists (e.g., a famous singer) and genres (e.g., Opera) do play a role (underlined by the number of disliked genres in Classical music in the current study).

With regard to the degree of dislike, reviewing the quantitative evaluation on how much participants disliked their mentioned music, about one third of the dislikes was at and below the midpoint of the rating scale, showing that music exists that is disliked to a lesser degree. Whether different rationales or certain individual variables such as personality or musical sophistication apply differently to strong and slight dislikes will need to be investigated in future studies. 


\section{Conclusion}

Conceptualizing musical dislikes being an inherent part of the concept of musical taste

648 and therefore an inherent part of music-related behavior and its consequences for everyday

649 life, this study showed the range and extent of the rationales underlying disliked music. While

650 musical dislikes have already been shown to fulfill important social functions, the current

651 study extends the rationales to music-related and self-related reasons.

652 Musical dislikes fulfill similar functions to liked music, such as preservation of a good

653 mood, identity expression and construction, strengthening of group cohesion as well as social

654 distinction. However, in contrast to the reasons behind liking, the justifications are mainly

655 related to very specific musical characteristics, the content, evoked feelings (or lack of), and

656 aesthetic expectations of the music.

657 The current study showed how many different aesthetic criteria underlie everyday

658 evaluations of music. Hence, focusing musical taste research exclusively on listeners' musical

659 preferences cannot account for this diversity.

660 


\section{References}

Ackermann, T.-I. (2014). Die Bedeutung des Musikhörens bei der Identitätskonstruktion im Jugendalter [Master Thesis]. Westfälische Wilhelms-Universität. https://www.researchgate.net/profile/TarenAckermann/publication/334194547_Die_Bedeutung_des_Musikhorens_bei_der_Identitats konstruktion_im_Jugendalter/links/5d1c7a61299bf1547c92f8f0/Die-Bedeutung-desMusikhoerens-bei-der-Identitaetskonstruktion-im-Jugendalter.pdf

Ackermann, T.-I. (2019). Disliked Music: Merkmale, Gründe und Funktionen abgelehnter Musik. Kassel University Press.

Anttonen, S. (2016). 'Hypocritical bullshit performed through gritted teeth': Authenticity discourses in Nickelback's album reviews in Finnish media. Metal Music Studies, 2(1), 39-56. https://doi.org/10.1386/mms.2.1.39_1

Bakagiannis, S., \& Tarrant, M. (2006). Can music bring people together? Effects of shared musical preference on intergroup bias in adolescence. Scandinavian Journal of Psychology, 47(129-136).

Banister, P., Burman, E., Parker, I., Taylor, M., \& Tindall, C. (1994). Qualitative methods in psychology: A research guide. Open University Press.

Becker, H. S. (2014). Außenseiter. Springer Fachmedien Wiesbaden. https://doi.org/10.1007/978-3-658-01254-0

Behne, K. E. (1986). Hörertypologien: Zur Psychologie des jugendlichen Musikgeschmacks. Perspektiven zur Musikpädagogik und Musikwissenschaft: Vol. 10. Gustav Bosse Verlag.

Behne, K. E. (1987). Urteile und Vorurteile: Die Alltagsmusiktheorien jugendlicher Hörer. In H. de La Motte-Haber (Ed.), Handbuch der Musikpädagogik: Vol. 4. Psychologische Grundlagen des Musiklebens (pp. 221-272). Bärenreiter.

Bennett, T., Savage, M., Silva, E., Warde, A., Gayo-Cal, M., \& Wright, D. (2010). Culture, class, distinction (Paperback ed.). Culture, economy, and the social. Routledge.

Berli, O. (2014). Grenzenlos guter Geschmack: Die feinen Unterschiede des Musikhörens (1. Aufl.). Kultur und soziale Praxis. transcript.

Berlyne, D. E. (1960). Conflict, arousal, and curiosity. McGraw-Hill Book Company. https://doi.org/10.1037/11164-000

Boer, D. (2009). Music makes the people come together: Social functions of music listening for young people across cultures [Thesis submitted in fulfillment of the requirements for the degree of Doctor of Philosophy, Victoria University of Wellington]. EndNote.

Boer, D., Fischer, R., Tekman, H. G., Abubakar, A., Njenga, J., \& Zenger, M. (2012). Young people's topography of musical functions: personal, social and cultural experiences with music across genders and six societies. Int J Psychol, 47(5), 355-369. https://doi.org/10.1080/00207594.2012.656128

Bonneville-Roussy, A., \& Rust, J. (2017). Age trends in musical preferences in adulthood: 2. Sources of social influences as determinants of preferences. Musicae Scientiae, 5(392), 102986491770401. https://doi.org/10.1177/1029864917704016

Bourdieu, P. (1984). Distinction: A social critique of the judgement of taste. Harvard University Press. https://www.hup.harvard.edu/catalog.php?isbn=9780674212770

Bryson, B. (1996). "Anything But Heavy Metal": Symbolic Exclusion and Musical Dislikes. American Sociological Review, 61(5), 884-899.

Chamorro-Premuzic, T [Tomas], Swami, V., \& Cermakova, B. (2012). Individual differences in music consumption are predicted by uses of music and age rather than emotional 
intelligence, neuroticism, extraversion or openness. Psychology of Music, 40(3), 285-300. https://doi.org/10.1177/0305735610381591

Chmiel, A., \& Schubert, E. (2017). Back to the inverted-U for music preference: A review of the literature. Psychology of Music, 45(6), 886-909. https://doi.org/10.1177/0305735617697507

Csíkszentmihályi, M. (2008). Flow: The Psychology of Optimal Experience. HarperCollins ebooks.

Cunningham, S. J., Downie, J. S., \& Bainbridge, D. (2005). "The pain, the pain": Modelling music information behavior and the songs we hate. In J. D. Reiss \& G. A. Wiggins (Chairs), Sixth International Conference On Music Information Retrieval. Symposium conducted at the meeting of Queen Mary, University of London, London.

DeNora, T. (2000). Music in everyday life. Cambridge University Press.

DiMaggio, P. (1987). Classification in Art. American Sociological Review, 52(4), 440. https://doi.org/10.2307/2095290

Dolfsma, W. (1999). The Consumption of Music and the Expression of Values: A Social Economic Explanation for the Advent of Pop Music. American Journal of Economics and Sociology, 58(4), 1019-1046.

Fabbri, F. (2012). How Genres are Born, Change, Die: Conventions, Communities and Diachronic Processes. In S. Hawkins (Ed.), Critical musicological reflections: Essays in honour of Derek B. Scott (pp. 179-191). Routledge Taylor \& Francis Group.

Fishbein, M., \& Ajzen, I. (1975). Belief, attitude, intention, and behavior: An introduction to theory and research. Addison-Wesley series in social psychology. Addison-Wesley Pub. Co.

Frith, S. (1987). Why do songs have words? In A. L. White (Ed.), The Sociological Review: Vol. 34. Lost in Music. Culture, Style and the Musical Event (77-106). Routledge \& Kegan Paul.

Frith, S. (2004). What is Bad Music? In C. Washburne \& M. Derno (Eds.), Bad music: The music we love to hate (pp. 15-36). Routledge.

Getz, L. M., Chamorro-Premuzic, T [T.], Roy, M. M., \& Devroop, K. (2011). The relationship between affect, uses of music, and music preferences in a sample of South African adolescents. Psychology of Music, 40(2), 164-178. https://doi.org/10.1177/0305735610381818

Grazian, D. (2010). Demystifying authenticity in the sociology of culture. In J. R. Hall, L. Grindstaff, \& M. M. Lo (Eds.), Routledge international handbooks. Handbook of cultural sociology (pp. 191-200). Routledge.

Greasley, A., Lamont, A., \& Sloboda, J. (2013). Exploring Musical Preferences: An In-Depth Qualitative Study of Adults' Liking for Music in Their Personal Collections. Qualitative Research in Psychology, 10(4), 402-427. https://doi.org/10.1080/14780887.2011.647259

Greb, F., Schlotz, W., \& Steffens, J. (2017). Personal and situational influences on the functions of music listening. Psychology of Music, 0305735617724883. https://doi.org/10.1177/0305735617724883

Hargreaves, D. J [D. J.], \& North, A. C. (1999). The Functions of Music in Everyday Life: Redefining the Social in Music Psychology. Psychology of Music, 27(1), 71-83. https://doi.org/10.1177/0305735699271007

Hines, M., \& McFerran, K. S. (2014). Metal made me who I am: Seven adult men reflect on their engagement with metal music during adolescence. International Journal of Community Music, 7(2), 205-222. https://doi.org/10.1386/ijcm.7.2.205_1 
Holstein, J. A., \& Gubrium, J. F. (1995). The active interview. Qualitative research methods: Vol. 37. Sage Publications.

Kaufmann, J.-C. (2015). Das verstehende Interview: Theorie und Praxis (2., überarbeitete Auflage). UVK.

Kroger, C., \& Margulis, E. H. (2017). "But they told me it was professional": Extrinsic factors in the evaluation of musical performance. Psychology of Music, 45(1), 49-64. https://doi.org/10.1177/0305735616642543

Kunz, A. (1998). Aspekte der Entwicklung des persönlichen Musikgeschmacks. Friedensauer Schriftenreihe. Peter Lang.

Laiho, S. (2004). The Psychological Functions of Music in Adolescence. Nordic Journal of Music Therapy, 13(1), 47-63. https://doi.org/10.1080/08098130409478097

Leech, B. L. (2002). Asking Questions: Techniques for Semistructured Interviews. Political Science \& Politics, 35(04), 665-668. https://doi.org/10.1017/S1049096502001129

Legard, R., Keegan, J., \& Ward, K. (2003). In-depth interviews. In J. Ritchie \& J. Lewis (Eds.), Qualitative Research and Practice: A Guide for Social Science Students and Researchers (pp. 138-169). Sage Publications.

Lehmann, M. (2018). Mit Metal zu Mozart: Präferenzen für "extreme" Musik in Hochkulturkontexten als Ausdruck musikalischer Toleranz. Samples, 16, 1-29. http://geb.uni-giessen.de/geb/volltexte/2018/13685

Lizardo, O., \& Skiles, S. (2012). Reconceptualizing and Theorizing “Omnivorousness". Sociological Theory, 30(4), 263-282. https://doi.org/10.1177/0735275112466999

Lizardo, O., \& Skiles, S. (2015). Musical taste and patterns of symbolic exclusion in the United States 1993-2012: Generational dynamics of differentiation and continuity. Poetics, 53, 9-21. https://doi.org/10.1016/j.poetic.2015.08.003

Lizardo, O., \& Skiles, S. (2016). The End of Symbolic Exclusion? The Rise of "Categorical Tolerance" in the Musical Tastes of Americans: 1993 -- 2012. Sociological Science, 3, 85108. https://doi.org/10.15195/v3.a5

Lonsdale, A. J., \& North, A. C. (2009). Musical Taste and Ingroup Favouritism. Group Processes \& Intergroup Relations, 12(3), 319-327.

Lonsdale, A. J., \& North, A. C. (2011). Why do we listen to music? A uses and gratifications analysis. British Journal of Psychology (London, England : 1953), 102(1), 108-134. https://doi.org/10.1348/000712610X506831

Mayring, P. (2014). Qualitative content analysis: Theoretical foundation, basic procedures and software solution. Social Science Open Access Repository SSOAR. http://nbnresolving.de/urn:nbn:de:0168-ssoar-395173

Merrill, J., \& Ackermann, T.-I. (2020). "Like static noise in a beautiful landscape": A mixedmethods approach to rationales and features of disliked voices in popular music. Psychology of Aesthetics, Creativity, and the Arts. Advance online publication. https://doi.org/10.1037/aca0000376

Merrill, J., \& Larrouy-Maestri, P. (2017). Vocal Features of Song and Speech: Insights from Schoenberg's Pierrot Lunaire. Frontiers in Psychology, 8, 1108. https://doi.org/10.3389/fpsyg.2017.01108

Misoch, S. (2015). Qualitative Interviews. Walter de Gruyter.

Moore, A. F. (2002). Authenticity as authentication. Popular Music, 21(02). https://doi.org/10.1017/S0261143002002131

Nave, G., Minxha, J., Greenberg, D. M., Kosinski, M., Stillwell, D., \& Rentfrow, J. (2018). Musical Preferences Predict Personality: Evidence From Active Listening and Facebook 
801

802

803

804

805

806

807

808

809

810

811

812

813

814

815

816

817

818

819

820

821

822

823

824

825

826

827

828

829

830

831

832

833

834

835

836

837

838

839

840

841

842

843

844

845

846
Likes. Psychological Science, 29(7), 1145-1158.

https://doi.org/10.1177/0956797618761659

North, A. C., Hargreaves, D. J [D. J.], \& Hargreaves, J. J. (2004). Uses of Music in Everyday Life. Music Perception: An Interdisciplinary Journal, 22(1), 41-77.

Ogilvie, D. M. (1987). The Undesired Self - a Neglected Variable in Personality-Research. Journal of Personality and Social Psychology, 52(2), 379-385. https://doi.org/10.1037/0022-3514.52.2.379

Parzer, M. (2011). Der gute Musikgeschmack: Zur sozialen Praxis ästhetischer Bewertung in der Popularkultur (1., Aufl.). Musik und Gesellschaft: Vol. 30. Lang.

Peltola, H.-R., \& Vuoskoski, J. K. (2021). "I hate this part right here": Embodied, subjective experiences of listening to aversive music. Psychology of Music, 030573562098859. https://doi.org/10.1177/0305735620988596

Peterson, R. A. (1992). Understanding audience segmentation:: From elite and mass to omnivore and univore. Poetics, 21, 243-258. http://ac.els-cdn.com/0304422X9290008Q/1s2.0-0304422X9290008Q-main.pdf?_tid=1d888cf6-8654-11e6-845700000aab0f02\&acdnat=1475160831_091cf9361809936e28eadec63c10f99a

Peterson, R. A. (2005). In Search of Authenticity. Journal of Management Studies, 42(5), 1083-1098. https://doi.org/10.1111/j.1467-6486.2005.00533.x

Peterson, R. A., \& Kern, R. M. (1996). Changing Highbrow Taste: From Snob to Omnivore. American Sociological Review, 61(5), 900-907.

Popper, R., \& Kroll, D. R. (2005). Just-About-Right Scales in Consumer Research. Chemo Sense, 7(3), 3-6.

Rentfrow, P. J. (2012). The Role of Music in Everyday Life: Current Directions in the Social Psychology of Music. Social and Personality Psychology Compass, 6(5), 402-416. https://doi.org/10.1111/j.1751-9004.2012.00434.x

Samson, J. (2001). Genre. Oxford University Pres.

Savage, M. (2006). The musical field. Cultural Trends, 15(2-3), 159-174. https://doi.org/10.1080/09548960600712975

Schäfer, T., \& Mehlhorn, C. (2017). Can personality traits predict musical style preferences? A meta-analysis. Personality and Individual Differences, 116, 265-273. https://doi.org/10.1016/j.paid.2017.04.061

Schäfer, T., \& Sedlmeier, P. (2009). From the functions of music to music preference. Psychology of Music, 37(3), 279-300. https://doi.org/10.1177/0305735608097247

Schäfer, T., \& Sedlmeier, P. (2010). What makes us like music? Determinants of music preference. Psychology of Aesthetics, Creativity, and the Arts, 4(4), 223-234. https://doi.org/10.1037/a0018374

Schäfer, T., Sedlmeier, P., Städtler, C., \& Huron, D. (2013). The psychological functions of music listening. Front Psychol, 4, 511. https://doi.org/10.3389/fpsyg.2013.00511

Schäfer, T., Tipandjan, A., \& Sedlmeier, P. (2012). The functions of music and their relationship to music preference in India and Germany. Int J Psychol, 47(5), 370-380. https://doi.org/10.1080/00207594.2012.688133

Schramm, H., \& Vorderer, P. (2002). Musikpräferenzen im Alltag. Ein Vergleich zwischen Jugendlichen und Erwachsenen. In W. Heitmeyer, K. Hurrelmann, J. Mansel \& U. Sander (Series Eds.) \& R. Müller, P. Glogner, S. Rhein \& J. Heim (Vol. Eds.), Jugendforschung. Wozu Jugendliche Musik und Medien gebrauchen. Jugendliche Identität und musikalische und mediale Geschmacksbildung (pp. 112-125). Juventa. 
847 Schreier, M. (2014). Varianten qualitativer Inhaltsanalyse: Ein Wegweiser im Dickicht der 848 Begrifflichkeiten. Forum Qualitative Sozialforschung, 15(1).

849 Schubert, E. (2013). Emotion felt by the listener and expressed by the music: Literature review and theoretical perspectives. Frontiers in Psychology, 4, 837.

$851 \quad$ https://doi.org/10.3389/fpsyg.2013.00837

852 Sloboda, J. A., O'Neill, S. A., \& Ivaldi, A. (2001). Functions of music in everyday life: an exploratory study using the Experience Sampling Method. Musicae Scientiae, 5(1), 9-32.

854 Steigleder, S. (2008). Die strukturierende qualitative Inhaltsanalyse im Praxistest: Eine konstruktiv kritische Studie zur Auswertungsmethodik von Philipp Mayring. Tectum-Verl.

Tarrant, M., North, A. C., \& Hargreaves, D. J [David J.] (2000). English and American Adolescents' Reasons for Listening to Music. Psychology of Music, 28(2), 166-173. https://doi.org/10.1177/0305735600282005

von Appen, R. (2007). Der Wert der Musik: Zur Ästhetik des Populären. Texte zur populären Musik: Vol. 4. transcript.

861 Woodward, I., \& Emmison, M. (2001). From aesthetic principles to collective sentiments: The logics of everyday judgements of taste. Poetics, 29, 295-316. https://doi.org/10.1016/S0304-422X(00)00035-8 